\title{
Author Correction: AMP kinase promotes glioblastoma bioenergetics and tumour growth
}

Rishi Raj Chhipa, Qiang Fan, Jane Anderson, Ranjithmenon Muraleedharan, Yan Huang, Georgianne Ciraolo, Xiaoting Chen, Ronald Waclaw, Lionel M. Chow (D), Zaza Khuchua, Matthew Kofron, Matthew T. Weirauch (iD, Ady Kendler, Christopher McPherson, Nancy Ratner, Ichiro Nakano, Nupur Dasgupta, Kakajan Komurov and Biplab Dasgupta (iD

Correction to: Nature Cell Biology https://doi.org/10.1038/s41556-018-0126-z, published online 18 June 2018.

In the version of this Article originally published, in ref. 34 the first author's name was spelled incorrectly. The correct reference is: Rodón, L. et al. Active CREB1 promotes a malignant TGF $\beta 2$ autocrine loop in glioblastoma. Cancer Discov. 10, 1230-1241 (2014). This has now been amended in all online versions of the Article.

\section{Retraction Note: Formin' a perinuclear actin cage in confined migration}

Alexia-lleana Zaromytidou

Retraction of: Nature Cell Biology https://doi.org/10.1038/ncb3547, published online 31 May 2017.

Given that the authors of 'FMN2 makes perinuclear actin to protect nuclei during confined migration and promote metastasis' (Skau et al. Cell 167, 1571-1585; 2016) have retracted their paper, I wish to retract this Research Highlight, which discussed the findings reported in that study. 